\title{
Double Haploids for Vegetable Crop Improvement: A Review
}

\author{
S. Aruna ${ }^{1}$, M. Rafeekher ${ }^{1}$, Pooja P. Gowda' ${ }^{1}$ Ajin S. Anil², V. Anjaly ${ }^{3}$
}

10.18805/ag.R-2300

\begin{abstract}
Vegetables are the richest source of vitamins and minerals and play a major role in nutritional security. The primary objective of vegetable breeding is enhancing production and productivity. Breeders use various conventional and non-conventional breeding approaches for genetic advance. Recent advances in biotechnology helps to enhance the efficiency and shorten the time required to achieve the fixed goals in a breeding program, as well as to address the economic and ecological goals. Among these, haploid $(\mathrm{H})$ and doubled haploid $(\mathrm{DH})$ production through gametic embryogenesis has long been recognized as a valuable tool to help crop improvement. Haploid plants are the sporophytes with a gametophytic chromosome number and doubled haploids (DH) are haploids that have undergone chromosome duplication. Haploids and double haploids occur spontaneously in nature. Haploids can also be induced artificially by various techniques such as wide hybridization, pollination with irradiated pollens androgenesis, gynogenesis and finally further chromosome doubling results in double haploids. Production of double haploids in vegetables will shorten the breeding cycle and also $\mathrm{DH}$ technology is useful in reverse breeding, CMS line production, gene stacking and various other genetic studies.
\end{abstract}

Key words: Androgenesis, Double haploid, Gynogenesis, Haploid.

Vegetables are the richest source of vitamins and minerals and play a major role in nutritional security. The most direct and affordable way to deliver better nutrition for all is to give more attention on vegetables. According to the recent reports by $\mathrm{FAO}$, consumption of a minimum of $400 \mathrm{~g}$ of fruit and vegetables per day (excluding potatoes and other starchy tubers) is necessary for prevention of chronic diseases such as heart disease, cancer, diabetes and obesity, as well as for alleviating several micronutrient deficiencies, especially in under developed countries. So, the first and foremost step towards this is obviously the expansion in the production as well as productivity of fruits and vegetables (Schreinemachers et al., 2018).

The major challenge faced in vegetable production is the various abiotic and biotic stresses. Plant breeding serves as a tool for introducing host plant resistance, developing stress tolerant varieties and cultivars with the desired produce quality. Besides these, the genetic enhancement of vegetables aims primarily on achieving higher production along with quality demand in the market (Dias and Ortiz, 2019). Vegetable crop improvement can be done by various conventional and non-conventional breeding approaches. Recent advances in biotechnology helps to enhance the efficiency and shorten the time required to achieve the target in a breeding program, as well as to address economic and ecological goals. Among these, haploid $(\mathrm{H})$ and doubled haploid $(\mathrm{DH})$ production through gametic embryogenesis has long been recognized as a valuable tool to help plant improvement (Ren et al., 2017).

Haploid plants are the sporophytes with a gametophytic chromosome number and doubled haploids $(\mathrm{DH})$ are haploids that have undergone chromosome duplication. Thus, in a diploid sporophytic (2n) species the haploids could also be called monoploid $(x)$ as they have only one set of chromosomes. In polyploid species, the haploids $(n)$ have
${ }^{1}$ Department of Vegetable Science, College of Agriculture, Kerala Agricultural University, Vellayani-695 522, Kerala, India.

2Division of Soil Science and Agricultural Chemistry, Indian Agricultural Research Institute, New Delhi-110 001, India.

${ }^{3}$ Department of Agronomy, Punjab Agricultural University, Ludhiana141 027, Punjab, India.

Corresponding Author: S. Aruna, Department of Vegetable Science, College of Agriculture, Kerala Agricultural University, Vellayani695 522, Kerala, India. Email: arunarchana122@gmail.com

How to cite this article: Aruna, S., Rafeekher, M., Gowda, P.P., Anil, A.S. and Anjaly, V. (2022). Double Haploids for Vegetable Crop Improvement: A Review. Agricultural Reviews. DOI: 10.18805/ ag. R-2300.

Submitted: 09-06-2021 Accepted: 04-12-2021 Online: 23-02-2022

more than one set of chromosomes and are polyhaploids. Dihaploid is a haploid plant from an autotetraploid $(4 x)$ and is not homozygous as it represents two chromosome sets selected from four sets in the autotetraploid (Germana, 2011)

\section{Double haploids}

Haploids are the sporophytes that contain a gametic chromosome number $(n)$ instead of normal somatic $(2 n)$ chromosome number (Murovec and Bohanec, 2012). Spontaneous occurrence of haploids was first ever reported in weed species, Datura stramonium (Blackeslee et al., 1922), followed by similar reports in several other crops (Chase, 2005; Dunwell, 2010; Maluszynski et al., 2003; Nanda and Chase, 1966; Riley, 1974). Even though the natural occurrences were reported in various species, the breakthrough in the field of haploid breeding was the production of haploids in vitro by anther culture in Datura sp (Guha and Maheshwari, 1964, 1966). Another milestone 
was the production of haploids by wide hybridization followed by chromosome elimination and embryo culture (Kasha and Kao, 1970). Later in 1974, chromosome doubling techniques for the production of homozygous double haploids from sterile haploids were established (Jensen, 1974) which accelerated the haploid research. The research on haploid or double haploid system and their exploitation has been increasing remarkably owing to the establishment of protocols for the double haploid induction in over 250 plant species (Maluszynski et al., 2003, Forster and Thomas, 2005).

\section{Why double haploids?}

The DHs obtained through various techniques are homozygous at all loci and they may be used as a new variety in the case of self-pollinating species whereas they serve as potential parental inbred line for the production of hybrids in cross-pollinated crops (Murovec and Bohanec, 2012). In conventional breeding, through inbreeding/ sibmating it will take around 6-7 generations to develop a homozygous line especially in biennials as well as those crops having long juvenile phase whereas within a single generation an inbred line can be developed via double haploidization (Bohanec, 2009; Prigge et al., 2012; Wedzony et al., 2009). Besides these, double haploids are relevant in those species having self-incompatibility or higher inbreeding depression on continuous selfing (Thaneswari et al., 2018). Double haploidy along with marker assisted selection can be used as an alternative option for backcross breeding which consumes more time. In mutation studies, double haploids provide the attractive features for fixing mutations. As double haploidy is a way to homozygosity with greater reliability, they can be used to fix mutations which are mostly recessive in nature or otherwise they can be directly used for mutation treatment so that we can capture the resulting mutation in pure homozygous condition (Szarejko and Forster, 2006).

In addition to the applications in crop improvement, double haploid systems aid in many genomic approaches like construction of genetic maps, QTL mapping and marker identification (Alheit et al., 2011; Forster and Thomas, 2005; Forster et al., 2007).

\section{Double haploid technology and its applications in vegetables}

\section{Haploidization via wide hybridization}

This involves both inter specific and inter generic hybridization followed by the parental chromosomal elimination (Murovec and Bohanec, 2012). It was first applied in barley, commonly known by the name, bulbosum technique. In barley, wide hybridization was done between cultivated barley, Hordeum vulgare $(2 n=2 x=14)$ as the female and wild $H$. bulbosum $(2 n=2 x=14)$ as the male which resulted in haploid. The hybrid embryo formed was containing the chromosomes of both parents. But, chromosomes of the wild relative were preferentially eliminated from the cells of developing embryo due to the failure of endosperm development, which lead to the production of a haploid embryo. The haploid embryo was then extracted and grown in vitro (Kasha and Kao, 1970).

Doubled haploids can be produced from tetraploid genotypes of Solanum tuberosum (cultivated potato) by pollination with the diploid potato species Solanum tuberosum L. Phureja Group (De Maine, 2003). In about $0.5 \%$ of pollinated ovules, both male sperm cells of Solanum tuberosum L. Phureja Group take part in formation of functional endosperm, which triggers the parthenogenic development of unfertilized egg cells. The best pollinator lines of Solanum tuberosum L. Phureja Group were bred for a dominant purple spot embryo marker, thus seeds containing haploid embryos can be easily distinguished from hybrid S. tuberosum x S.phureja seeds. Methods of chromosome duplication were developed more recently and production of potato can be obtained by androgenic methods with a better efficiency (Jacobsen et al., 1993).

\section{Haploidization via pollination with irradiated pollen}

Maternal haploids can be obtained in vivo by using pollen that has been irradiated (using gamma rays from cobalt60 ) or pollen collected from a triploid plant. As this pollen fail to fertilize the egg cell, there won't be fertilization. However, pollination stimulates the development of haploid embryo (Musial and Przywara, 1998). Here, the success relies on the donor plant genotype and its growing condition radiation source and dose, the developmental stage embryos, the culture conditions and the media composition and also chromosome doubling and ploidy identification (Zhang et al., 2006; Lim and Earle 2008, 2009; Germana, 2011; Solmaz et al., 2011; Nasertorabi et al., 2012; Tas,kın et al., 2013; Baktemur et al., 2013, 2014; Kaur et al., 2019).

Pollination with irradiated pollen is the potent way to obtain haploids in the case of cucurbits. First ever haploid induction was successfully done in musk melon, Cucumis melo, by using irradiated pollen from $C$. ficifolius. This technique was successfully used to obtain haploid embryos by in vitro culturing (Sauton and de Vaulx, 1988). Later this technique was successfully employed in other cucurbits viz. cucumber (Lei et al., 2006; Dolcet-Sanjuan et al., 2006; Lofti and Salehi, 2008 and Shariatpanahi and Ramezanpour, 2019), watermelon (Sari et al., 1994), summer squash (Kurtar et al., 2002; Kurtar et al., 2017), pumpkin (Kurtar et al., 2009) and winter squash (Kurtar and Balkaya, 2010), melon (Ari et al. 2010; Godbole and Murthy 2012; Pamuk et al., 2018; Hooghvorst et al., 2020;), carrot (Rode and de Vaulx 1987).

\section{Haploidization via gynogenesis}

In vitro induction of maternal haploids, so-called gynogenesis, is induction of haploid embryos from the haploid cells, especially the unfertilized egg cell inside female gametophyte. Usually, in vitro culture of un-pollinated flower parts, such as ovules, placenta attached ovules, ovaries or whole flower buds is done to obtain the haploid plants. Gynogenic induction using unpollinated flower parts has been successful in several species, such as onion, sugar 
beet, cucumber, squash, gerbera, sunflower, wheat, barley etc. (Forster et al., 2007, Thaneswari et al., 2018). But its application in breeding is mainly restricted to onion and sugar beet. The success of the method and its efficiency is greatly influenced by several biotic and abiotic factors. The genotype of donor plants, combined with growth conditions, is the crucial factor (Badu et al., 2017).

In onion, anther culture is not successful and gynogenesis is the only rule for haploid induction (Keller and Korzun, 1996; Musial et al., 2001). It is made possible using the flower buds or unfertilized ovaries (Campion and Azzimonti, 1988). The success of recovery of the haploid regenerants in onion depends mainly on the genotype/variety, stage ovule development, pre-treatments given and the composition of culture media (Juokevieiene et al., 2005; Mathapati et al., 2018; Khar et al., 2019). The response to gynogenesis also depends up on the length of flower bud taken for in vitro culture (Michalik, 2000; Fayos et al., 2011). Among the Indian short day cultivars, gynogenic potential was found to be highest in Bhima Shubhra (Anandhan et al., 2014).

In tomato, gynogenic haploid induction is an alternative way for anther culture and a successful report on gynogenesis in tomato were given by various researchers (Bal and Abak, 2007). Gynogenesis might become a potential tool for haploidization in tomato in the coming era (Zhao et al., 2014).

Gynogenesis is a potential route for haploid breeding in cucurbits (Dong et al., 2016). Successful protocols on in vitro culture of unfertilized ovule/ovary have been established in squash (Metwally et al., 1998; Zou et al., 2020), pumpkin (Sun et al., 2009; Min et al., 2016), cucumber (Ge 'mesne-Juha 'sz et al., 2002; Sorntip et al., 2017) and melon (Beharav and Cohen 1995; Ficcadenti et al., 1999). In cucumber, it has been reported that unpollinated ovule culture could be done in cucumber basal medium containing thidiazuron and silver nitrate (Li et al., 2013). Further, the effect of various genotypes and culture media were studied various researchers in cucumber (Ozsan et al., 2017), onion (Fayos et al., 2011) etc.

Gynogenesis is the least favoured technique for induction of haploids as it is having low efûciency and is limited to only those species which fail to respond to other efficient methods (Forster et al., 2007).

\section{Haploidization via androgenesisa}

\section{a. Haploidization via in vitro cultured anthers}

The technique of production of double haploids using anther culture is the mostly adapted in most of the crop species (Maluszynski et al., 2003). This is relatively a simple and less expensive method, even though precise study is hindered by the presence of extraneous sporophytic tissues such as anther wall (Forster et al., 2007). Anther culture involves the collection of flower buds followed by pretreatment, surface sterilization, dissection of anthers and finally placing the anthers into the medium (Germana, 2011). Similar to gynogenesis, anther culture is highly influenced by various factors, such as genotype (Dumas de Vaulx et al.,
1981; Ltifi and Wenzel, 1994), donor plant culture conditions (Kristiansen and Andersen, 1993)., pretreatment of flower buds or anthers (Dumas de Vaulx, 1981; Oskum et al., 2001; Supena et al., 2006), stage of development of microspore (Lantos et al. 2009; Kim et al. 2004), culture medium composition and culture conditions (Gudeva et al. 2007). Shed microspore culture is a slight modification in the anther culture in which the anther is stimulated to dehisce and the released microspores are cultured. This is successfully employed in pepper (Supena et al., 2006).

List of vegetable crops in which anther culture is possible

\begin{tabular}{ll}
\hline Vegetables & References \\
\hline Asparagus & Tsay, 1996; Peng and Wolyn, 1999 \\
Broccoli & Qin et al., 2015 \\
Cauliflower & Arnison and Keller, 1990; Bhattacharya et al., 2017 \\
Brinjal & Kumar et al., 2003; Basay et al., 2013; \\
& Bhattacharya et al., 2019 \\
Capsicum & Hegde et al., 2017 \\
Tomato & Bal and Abak, 2007; Kumar et al., 2020 \\
Chilli & George and Narayanaswamy, 1973; Kristiansen \\
& and Andersen, 1993; Kim et al., 2008; Gudeva \\
Summer squash & et al., 2009; \\
Carrot & Anderson, 1985 et al., 1998 \\
Potato & Aboshama and Atwa, 2020 \\
Musk melon & Song et al., 2007 \\
Cucumber & Song et al., 2007 \\
\hline
\end{tabular}

\section{b. Haploidization via isolated microspore culture}

It has got several advantages as compared to that of anther culture. Removal of anther wall helps to avoid the embryogenesis from saprophytic tissues and more precise studies could be conducted as single cell is being manipulated (Touraev et al., 2001). Two alternative methods of microspore isolation are commonly used. Flowers at the optimal developmental stage are cut by hand or blended, microspores are then separated from the debris by a series of washes, sieving and/or centrifugation steps (Zaki and Dickinson, 1990). In the second method, anthers are manually isolated from flowers and placed in liquid medium containing mannitol where the microspores are spontaneously released into the medium and then filtered or separated by centrifugation and re-suspended in the induction medium (Touraev et al., 1996).

List of vegetable crops in which isolated microspore culture is possible

\begin{tabular}{ll}
\hline Vegetables & References \\
\hline Turnip & Zhang et al., 2012; Shumilina et al., 2020 \\
Carrot & Kiszczak et al. 2017; Shmykova et al., 2021 \\
Chinese cabbage & Sato et al., 1989 \\
Brinjal & Corral-Martínez et al., 2012 \\
Radish & Tuncer, 2017 \\
Cauliflower & Bhatia et al., 2017 \\
Broccoli & Dias, 2001 \\
\hline
\end{tabular}




\section{Chromosome doubling}

Double haploids can occur spontaneously, but in most cases. Chromosome doubling of haploids is required to restore fertility.

\section{Methods of chromosome doubling (Diploidization)}

1.Endomitosis: Endomitosis is described as chromosome multiplication and seperation but failure of spindle leads to one restitution nucleus with chromosome number doubled. It has also been called 'Nuclear Restitution'.

2. Endoreduplication: Endoreduplication is a phenomenon of DNA or chromosome doubling without Cytokinesis.

3. C-mitosis: C-mitosis is nothing but endomitosis under the influence of colchicine.

4. Nuclear fusion: it occurs when two or more nuclei divide synchronously and develop a common spindle. Thus, two or more nuclei could result with doubled, polyploid or aneuploid chromosome number.

\section{Chromosome doubling agents}

1. Acenanaphthene

2. Chloramphenicol

3. Nitrous oxide

4. Parafluorophenyl alanine

5. 8- hydroxyquinone

6. Colchicine

\section{Colchicine}

It is the most commonly used doubling agent which can be applied in vivo (Kasha et al., 2005). It is an alkaloid isolated by French chemists P.S. Pelletier and J. Caventon in 1820. It is a toxic natural alkaloid and secondary metabolite, extracted from plants of the Genus Colchicum (autumn crocus, Colchicum autumnale, also known as "meadow saffron"). It is extracted from seeds and corms of Colchicum. It increases fertile plant regeneration and reduce albinism in anther culture. The systematic (IUPAC) name for colchicine is $\mathrm{C}_{22} \mathrm{H}_{25} \mathrm{NO}_{6}$. Colchicine acts by inhibiting microtubule polymerization by binding to tubulin. Mitosis will not take place without the availability of tubulin and therefore colchicine effectively functions as a "mitotic poison" or "spindle poison".

\section{Methods of colchicine application}

The optimum concentration as well as time of application of chromosome doubling may have negative impacts on embryogenesis, regeneration rate, as well as on the percentage of green plants (Castillo et al., 2009). The different methods adopted are:

1. Seed treatment $(0.001$ to $1 \% ; 0.2 \%$ is more common).

2. Germinating seed treatment.

3. Growing shoot apex (0.1 to $1 \%$ Colchicine).

4. Treatment of growing point in the cotyledonary stage.

5 . Colchicine in glycerine $(0.2-0.4 \%$ colchicine in $10 \%$ glycerine $)$.

6. Colchicine in emulsion (0.2-0.4\% colchicine).

7. Colchicine in agar ( $1 \%$ colchicine and $2 \%$ agar mixed in equal parts).
Among all methods of colchicine application, shoot apex treatment at the seedling stage is most effective

\section{Checking of ploidy level}

Finally, after treating with the chromosome doubling agent the ploidy level of treated plant should be checked. There are several direct and indirect methods for determining the ploidy level. Indirect approaches based on comparisons between regenerated and donor plants in terms of plant morphology (plant height, leaf dimensions and flower morphology), plant vigour and fertility. Though the indirect methods are less expensive, much unreliable as it is influenced by environmental effects. Direct methods are more robust and reliable and include conventional cytological techniques, such as counting the chromosome number in root tip cells (Maluszynska, 2003) and measurement of DNA content using flow cytometry (Bohanec, 2009) Direct methods provide a rapid and simple option for large-scale ploidy determination as early as in the in vitro culturing phase. It also enables detection of mixoploid regenerants (having cells with different ploidy) and the determination of their proportion.

\section{Applications of DHs in vegetable breeding}

- Cultivar development.

- Mutation studies.

- Mapping quantitative trait loci.

- Backcross breeding.

- Production of biotic and abiotic stress resistant plants.

- Construction of genetic maps.

- Genomic studies.

\section{Limitations of DHs}

- Haploids cannot be obtained in high frequency required for selection.

- Selection cannot be imposed a double haploid population.

- The cost benefit ratio in haploid breeding is often very high, discouraging the use despite of its obvious advantages.

- Haploids will express recessive deleterious traits.

- Deleterious mutations may arise during anther culture.

- In haploids produced from anther culture, it is observed that some plants are aneuploids and some are mixed haploiddiploid types.

- The over-usage of doubled haploidy may reduce genetic variation in breeding germplasm.

- Other constraints associated with use of this technology are the low rate of embryogenesis and regeneration, high frequency of albinism, segregation distortion and the low frequency of chromosome doubling to obtain DH (Dunwell, 2010).

\section{CONCLUSION}

Double haploid is a plant or line obtained by doubling the chromosome number of a haploid plant or individual. In vivo and in vitro methods have been used to produce $\mathrm{DH}$. The genetic upgradation of crops through conventional breeding approaches takes longer period. So, there is a need to assist 
these methods with certain biotechnological tools to shorten the breeding cycle. Double Haploid (DH) breeding is one such tool which has got great potential in breeding programmes in the upcoming future.

\section{Conflicts of Interest: None.}

\section{REFERENCES}

Aboshama, H.M. and Atwa, M.M. (2020). Anther culture in potato (Solanum tuberosum L.) in vitro. J. Plant Biol. Agric. Sci. 1: 21-30.

Alheit, K.V., Reif, J.C., Maurer, H.P., Hahn, V., Weissmann, E.A., Miedaner, T. and Würschum, T. (2011). Detection of segregation distortion loci in triticale based on a highdensity DArT marker consensus genetic linkage map. BMC Genomics. 12(1): 380-398.

Anandhan, S., Chavan, A.A., Gopal, J., Mote, S.R., Shelke, P.V. and Lawande, K.E. (2014). Variation in gynogenic potential for haploid induction in Indian short-day onions. Indian J. Genet. 74(2): 526-528.

Andersen, S.B. (1985). Anther Culture in Carrot. In: Proc. $1^{\text {st }}$ Nordic Cell and Tissue Culture Symp. Research, Breeding and Production of Crop Plants. [Bornman, C.H., Heneen, W.K., Jensen, C.J., Lundqvist, A. (eds)]. Hered. Suppl. 3: 132 (Abstr).

Ari, E., Ikten, H., Gocmen, M., Coskun, R. and Eren, A. (2010). Comparative evaluation of different embryo rescue techniques on parthenogenetic melon (Cucumis melo L.) fruits induced with irradiated pollen. Afr. J. Biotechnol. 9(33): 5347-5356

Arnison, P.G., Donaldson, P. and Kellar, W.A. (1990). The influence of various physiological parameters on anther culture of broccoli (Brassica oleracea var. italica). Plant Cell Tissue Organ Culture. 20:147-154.

Badu, M., Tripathy, B., Sahu, G.S. and Jena, A.K. (2017). Role of doubled haploids in vegetable crop improvement. J. Pharmacognosy and Phytochemistry. 6(6): 384-389.

Baktemur, G., Tas,kın, H., Kalaca, S. (2013). Comparison of different methods for separation of haploid embryo induced through irradiated pollen and their economic analysis in melon (Cucumis melo var. inodorus). Sci. World J. 10: 1-7.

Baktemur, G., Yucel, N.K., Taskýn, H.,"mlekc, iog \u, S., kalaca, S. (2014). Effects of different genotypes and gamma ray doses on haploidization using irradiated pollen technique in squash. Turk. J. Biol. 38(3): 318-327.

Bal, U., Abak, K. (2007). Haploidy in tomato (Lycopersicon esculentum Mill.): A critical review. Euphytica. 158: 1-9.

Basay, S. and Şebnem, S. (2013). Effect of genotypical factors on the effectiveness of anther culture in eggplant (Solanum melongena L.). Turk. J. Biol. 37: 499-505.

Beharav, A. and Cohen, Y. (1995). Effect of kinetin and GA3 on in vitro ovule embryo culture of Cucumis melo L. Plant Growth Regul. 16(3): 267-269.

Bhatia, R., Dey, S.S., Sood, S., Sharma, K., Parkash, C. and Kumar, R. (2017). Efficient microspore embryogenesis in cauliflower (Brassica oleracea var. botrytis L.) for development of plants with different ploidy level and their use in breeding programme. Scientia Horticulturae. 216: 83-92.
Bhattacharya, A., Palan, B.V., Mali, K. and Char, B. (2017). Exploiting double haploidy in cauliflower (Brassica oleracea var. botrytis L.) for crop improvement. J. Applied Hortic. 19(2): 101-105

Bhattacharya, A., Sonone, Y. and Char, B. (2019). Improvement in tissue culture-assisted induction of double haploidy in brinjal (Solanum melongena L.). J. Appl. Hortic. 21(3): 178-181.

Blakeslee, A.F., Belling, J., Farnham, M.E. and Bergner, A.D. (1922). A haploid mutant in the Jimson weed, Datura stramonium. Sci. 55: 646-647.

Bohanec, B. (2009). Doubled haploids via gynogenesis. In: Advances in Haploid Production in Higher Plants. [Touraev, A., Forster, B.P. and Jain, S.M.] Springer Science + Business Media B.V, ISBN 978-1-4020-8853-7. pp. 35-46.

Campion, B. and Azzimonti, M. T. (1988). Evolution of Ploidy Level in Haploid Plants of Onion (Allium cepa) Obtained through in vitro Gynogenesis. Proceeding of $4^{\text {th }}$ Eucarpia Allium Symposium. Institute of Horticultural Research, Wellesbourne, Warwick, U.K. pp 6-9.

Castillo, A.M., Cistué, L., Vallés, M.P., Soriano, M. (2009). In: Advances in Haploid Production in Higher Plants. Chromosome Doubling in Monocots; [Forster, B.P., Touraev, A., Mohan Jain, S (ed)]. Springer, pp. 329-338.

Chase, S.S. (2005). Utilization of Haploids in Plant Breeding. In: Proc. Int. Symp. Haploids in Higher Plants. [Kasha, K.J. (Ed.)], Univ. Gulph, Ontario, Canada, pp. 211-230.

Corral-Martínez, P., Seguí-Simarro, J.M. (2012). Efficient production of callus-derived doubled haploids through isolated microspore culture in eggplant (Solanum melongena L.). Euphytica. 187: 47-61. https://doi.org/10.1007/s10681012-0715-z

De Maine, M.J. (2003). Potato Haploid Technologies. In Doubled Haploid Production in Crop Plants- A Manual.: [Maluszynski, M., Kasha, K.J., Forster, B.P. and Szarejko, I. (eds)], Kluwer, Dordrecht/Boston/London, pp. 241-247.

Dias, J.C.D. (2001). Effect of incubation temperature regimes and culture medium on broccoli microspore culture embryogenesis. Euphytica. 119: 389-394.

Dias, J.S. and Ortiz, R. (2019). Advanced Breeding Tools in Vegetable Crops. In: Prime Archives in Agricultural Research. [Dias, J. S. (Ed)].Hyderabad, India: Vide Leaf.

Dolcet-Sanjuan, R., Claveria, E. and Garcia-Mas, J. (20060. Cucumber (Cucumis sativus L.) dihaploid line production using in vitro rescue of in vivo induced parthenogenic embryos. Acta Hortic. 725(2): 837-844.

Dong, Y., Zhao, W., Li, X., Liu, X., Gao, N., Huang, J., Wang, W., $\mathrm{Xu}, \mathrm{X}$. and Tang, Z. (2016). Androgenesis, gynogenesis and parthenogenesis haploids in cucurbit species. Plant Cell Rep. 35: 1991-2019.

Dumas de Vaulx, R. (19810. Obtention de plantes haploides chez le melon (Cucumis melo L.) apres pollinisation par Cucumis ûcifolius. A. Rich CR Acad. Sci. 289: 875-878.

Dunwell, J.M. (2010). Haploids in flowering plants: Origins and exploitation. Plant Biotechnol. J. 8: 377-424.

Fayos, O., Vallés, M.P., Garcés-Claver, A., Mallor, C., Castillo, A.M. (2011). Doubled haploid production from Spanish onion (Allium cepa L.) germplasm: Embryogenesis induction, plant regeneration and chromosome doubling. Front. Plant Sci. 6: 384. 
Ficcadenti, N., Sestili, S., Annibali, S., Marco, M. D. and Schiavi, M. (1999). In vitro gynogenesis to induce haploid plants in melon (Cucumis melo L.). J. Genet. Breed. 53(3): 255-257.

Forster, B.P. and Thomas, W.T.B. (2005). Doubled haploids in genetics and plant breeding. Plant Breed. Rev. 25: 57-88.

Forster, B.P., Heberle-Bors, E., Kasha, K.J. and Touraev, A. (2007). The resurgence of haploids in higher plants. Trends in Plant Sci. 12(8): 368-375.

Ge 'mesne-Juha 'sz, A., Balogh, P., Ferenczy, A. and Kristo, Z. (2002). Effect of optimal stage of female gametophyte and heat treatment on in vitro gynogenesis induction in cucumber (Cucumis sativus L.). Plant Cell Rep. 21(2): 105-111.

George, L. and Narayanaswamy, S. (1973). Haploid capsicum through experimental androgenesis. Protoplasma. 78: 467-470.

Germana, M.A. (2011). Anther culture for haploid and doubled haploid production. Plant Cell Tissue Organ Cult. 86: 131146.

Godbole, M. and Murthy, H.N. (2012). In vitro production of haploids via parthenogenesis in culinary melon (Cucumis melon var. acidulus). Indian. J. Biotechnol. 11(4): 495-497.

Gudeva, K. L., Spasenoski, M. and Trajkova, F. (2007). Somatic embryogenesis in pepper anther culture: The effect of incubation treatments and different media. Scientia Hortic. 111: 114-119.

Gudeva, K.L., Trajkova, F., Dimeska, G. and Spasenoski, M. (2009). Androgenesis efficiency in anther culture of pepper (Capsicum annuum L.). Acta Hortic. 830: 183-190.

Guha, S. and Maheshwari, S.C. (1966). Cell division and differentiation of embryos in the pollen grains of Datura in vitro. Nat. 212: $97-98$.

Guha, S. and Maheshwari, S.C. (1964). In vitro production of embryos from anthers of Datura. Nat. 204: 497-524.

Hegde, V.P.S., Partap, R.C., Yadav and Baswana, K.S. (2017). In vitro androgenesis in Capsicum (Capsicum annuum L.). Int. J. Curr. Microbiol. App. Sci. 6(5): 925-933.

Hooghvorst, I., Torrico, O. and Hooghvorst, S. and Nogués, S. (2020). In situ parthenogenetic doubled haploid production in melon "Piel de Sapo" for breeding purposes. Frontiers in Plant Sci. 11: 378-382.

Jacobsen, E., Malvar, R., Huigen, D.J., Bergervoet, J.E.M. and Ramanna, M.S. (1993). Isolation and characterisation of somatic hybrids of diploid Solanum tuberosum and Solanum brevidens and the use of amylose free starch mutation for detection of introgression. Euphytica. 69: 191-201.

Jensen, C.J. (1974). Chromosome Doubling Techniques in Haploids. In: Haploids in Higher Plants. Advances and Potential. In: [Kasha, K.J. (ed.)]. Proceedings of the First International Symposium. Guelph University Press. pp. 153-190.

Juğkevièienë, D., Stanys, V. and Bobinas, È. (2005). Gynogenesis pecularities of Allium L. vegetables grown in Lithuania. Biologija. 3: 6-9.

Kasha, K. and Kao, K. (1970). High frequency haploid production in barley (Hordeum vulgare L.). Nat. 225: 874-876.

Kaur, H.A., Sharma, S.P., Kalia, A. and Sarao, N.K. (2019). Effect of irradiation on in vitro pollen germination of muskmelon (Cucumis melo L.). Veg. Sci. 46 (1 and 2).
Keller, E.R.J. and Korzun. L. (1996). Ovary and ovule culture for haploid production. In: In Vitro Haploid Production in Higher Plants, Vol. 1: Fundamental Aspects and Methods. [(Ed.) Jain, S.M., Sopory, S.K. and Veilleux. R.E.] Kluwer Academic Publishers, Dordrecht, the Netherlands. 217-235.

Khar, A., Islam, S., Kalia, P., Bhatia, R. and Kumar, A. (2019). Present status of haploidy research in onion (Allium cepa) - A review. Indian J. of Agric. Sci. 89 (3): 396-405.

Kim, M., Jang, I.C., Kim, J.A., Park, E.J., Yoon, M. and Lee, Y. (2008). Embryogenesis and plant regeneration of hot pepper (Capsicum annuum L.) through isolated microspore culture. Plant Cell Rep. 27: 425-434.

Kim, M., Kim, J., Yoon, M., Choi, D.I. and Lee, K.M. (2004). Origin of multicellular pollen and pollen embryos in cultured anthers of pepper (Capsicum annuum). Plant Cell, Tissue Organ Cul. 77: 63-72.

Kiszczak, W., Kowalska, U., Kapuścińska, A., Burian, M. and Górecka, K. (2017). Comparison of methods for obtaining doubled haploids of carrot. Acta Societatis Botanicorum Poloniae. 4: 1-10.

Kristiansen, K. and Andersen, S.B. (1993). Effects of donor plant temperature, photoperiod and age on anther culture response of Capsicum annuum L. Euphytica. 67: 105109.

Kumar, S., Jindal, S.K. and Dhaliwal, M.S. (2020). Callus induction and plant regeneration of tomato through anther culture. Veg. Sci. 47(1): 23-271.

Kumar, S., Singh, M., Prabhavathi, K. and Mathews, A. (2003). In vitro induction of haploid in eggplant (Solanum melongena L.). NewsI. Indian Institute of Vegetable Research. 22: 147-150.

Kurtar, E.S. and Balkaya, A. (2010). Production of in vitro haploid plants from in situ induced haploid embryos in winter squash (Cucurbita maxima Duchesne ex Lam.) via irradiated pollen. Plant Cell Tissue Org. Cult. 102(3): 267-277.

Kurtar, E.S., Balkaya, A., Göçmen, M. and Karaağaç, O. (2017). Dihaploidization in squash genotypes (Cucurbita spp) as a rootstock candidates for cucumber (Cucumis sativus L.) via irradiated pollen technique. Selcuk J. of Agric. and Food Sci. 31(1): 34-41.

Kurtar, E.S., Balkaya, A., Ozbakir, M. and Oûuoglu, T. (2009). Induction of haploid embryo and plant regeneration via irradiated pollen technique in pumpkin (Cucurbita moschata Duchesne ex. Poir). Afr. J. Biotechnol. 8(21): 5944-5951.

Kurtar, E.S., Sari, N., Abak, K. (2002). Obtention of haploid embryos and plants through irradiated pollen technique in squash (Cucurbita pepo L.). Euphytica. 127(3): 335-344.

Lantos. C., Juhasz, A.G., Somogyi, G., Otvos, K., Vagi, P., Mihaly, R., Kristof, Z., Somogyi, N. and Pauk, J. (2009). Improvement of isolated microspore culture of pepper (Capsicum annuum L.) via co-culture with ovary tissues of pepper or wheat. Plant Cell Tissue Organ Cult. 97: 285-293.

Lei, C., Chen, J.F., Qian, C.T., Zhang, X.Q., Zhang, Y.B. (2006). Studies on induction of haploid cucumbers by irradiated pollen pollination and their characterization. Sci Agric. Sin. 39(7): 1428-1436.

Li, J.W., Si, S.W. and Cheng, J.Y. (2013). Thidiazuron and silver nitrate enhanced gynogenesis of unfertilized ovule cultures of Cucumis sativu. Biol Plant. 57: 164-168. 
Lim, W., Earle, E.D. (2008). Effect of in vitro and in vivo colchicine treatments on pollen production and fruit recovery on melon plants obtained after pollination with irradiated pollen. Plant Cell Tiss. Org. Cult. 95(1): 115-124.

Lim, W., Earle, E.D. (2009). Enhanced recovery of doubled haploid lines from parthenogenetic plants of melon (Cucumis melo L.). Plant Cell Tiss. Org. Cult. 98: 351-356

Lofti, M., Salehi, S. (2008). Detection of Cucumber Parthenogenic Haploid Embryos by ûoating the Immature Seeds in Liquid Medium. In: Proceeding of IX $\mathrm{X}^{\text {th }}$ EUCARPIA Meeting on Genetics and Breeding of Cucurbitaceae. [Pitrat, M. (ed)]. Avignon, France, pp 375-380.

Ltifi, A. and Wenzel, G. (1994). Anther culture of hot and sweet pepper (Capsicum annum L.): Influence of genotype and plant growth temperature. Nwsl. 13: 74-77.

Maluszynska, J. (2003). Cytogenetic Tests for Ploidy Level Analyseschromosome Counting. In: Doubled Haploid Production in Crop Plants: A Manual. [Maluszynski, M., Kasha, K. J., Forster, B. P. and Szarejko, I.] pp. 391-395.

Mathapati, G.B., Kalia, P., Islam, S., Saini, N., Kumar, A. and Khar, A. (2018). Inûuence of Culture Media and Their Compositions on Haploid Induction in Indian Short-Day Onion. Proc. Natl. Acad. Sci., India, Sect. B Biol. Sci. pp. 189-198.

Metwally, E.I., Moustafa, S.A., El-Sawy, B.I., Haroun, S.A. and Shalaby, T.A. (1998). Production of haploid plants from in vitro culture of unpollinated ovules of Cucurbita pepo L. Plant Cell Tiss. Org. Cult. 52(3): 117-121.

Michalik, B. (2000). Gynogenesis in Polish onion cultivars. J. Plant Physiol. 156: 211-216.

Min, Z.Y., Li, H., Zou, T., Tong, L., Cheng, J. and Sun, X.W. (2016). Studies of in vitro culture and plant regeneration of unfertilized ovary of pumpkin. Chin. Bull. Bot. 51(1): 74-80.

Murovec, J. and Bohanec, B. (2012). Haploids and doubled haploids in plant breeding. In: Plant Breeding. [Abdurakhmonov, I. (Ed.)], In Tech Europe, Croatia. ISBN: 978-953-307-9325, pp. 87-106

Musial, K. and Przywara, L. (1998). Influence of irradiated pollen on embryo and endosperm development in Kiwifruit. Ann. Bot. 82: 747-756.

Musial, K., Bohanec, B. and Przywara, L. (2001). Embryological study on gynogenesis in onion (Allium cepa L.). Sex. Plant Reprod. 13: 335-341.

Nanda, D. and Chase, S. (1966). An embryo marker for detecting monoploids of maize (Zea mays L.). Crop Sci. 6: 213-215.

Nasertorabi, M., Madadkhah, E., Moghbeli, H., Roain, A. and Moghbeli, E. (2012). Enhanced production of doubled haploid lines from parthenogenetic Iranian melon plants obtained of irradiated pollen (Cucumis melo L.). Int. Res. J. Appl. Basic Sci. 3(8): 1595-1600.

Oskum, D., Tipirdamaz, R. and Ellialtioglu, S. (2001). The relationship between the endogenous abscisic acid content of anthers and in vitro androgenesis in Peppers (Capsicum annuum L.). In: IV ISHA. International Symposium on In vitro culture and horticultural breeding. Acta Hortic. 560: 327-329.

Pamuk, N., Sari, I., Solmaz, I. and Mancak. (2018). Development of double-haploid lines in Galia-type melons (Cucumis melo var. cantalupensis) using in vitro colchicine treatments: XXX International Horticultural Congress IHC2018: II International Symposium on Plant Breeding in Horticulture. Acta Hortic. 1282p.
Peng, M. and Wolyn, D.J. (1999). Improved callus formation and plant regeneration for shed microspore culture in asparagus (Asparagus officinalis L.). Plant Cell. Rep. 18: 954-958.

Prigge, V., Xu, X., Li, L., Babu, R., Chen, S., Atlin, G.N. and Melchinger, A. E. (2012). New insights into the genetics of in vivo induction of maternal haploids, the backbone of doubled haploid technology in maize. Genet. 190: 781793.

Qin, Y., Huang, Y., Pulli, S. and Guo, Y. (2015). Comparison of anther and microspore culture in androgenic embryogenesis and regeneration of broccoli [Brassica oleracea (L.) var. italica P.]. Afr. J. of Biotechnol. 14(42): 2910-2916.

Ren, J., Wu, P., Trampe, B., Tian, X., Lubberstedt, T. and Chen, S. (2017). Novel technologies in doubled haploid line development. Plant Biotechnol. J. 15: 1361-1370.

Riley, R. (1974). The Status of Haploid Research. in haploids in higher plants. In: Proceedings of the First International Symposium. [Kasha, K.J. (ed.)]. Guelph University Press, pp. 3-9.

Rode, J. C., Dumas de Vaulx, R. (1987). Obtention de plantes haploides de carotte (Daucus carota L.) issue de parthe 'nogene 'se in situ par du pollen irradie' et culture in vitro de graines immatures. C R Acad Sci Paris Ser III. 305: 225-229

Sari, N., Abak, K., Pitrat, M., Rode, J.C. and Dumas de Vaulx, R. (1994). Induction of parthenogenetic haploid embryos after pollination by irradiated pollen in watermelon. Hortic Sci. 29(10): 1189-1190.

Sato, T., Nishio, T. and Hirai, M. (1989). Plant regeneration from isolated microspore cultures of Chinese cabbage (Brassica campestris spp. pekinensis). Plant Cell Reports. 8: 486488.

Sauton, A. and Dumas de Vaulx, R. (1988). Doubled Haploid Production in Melon (Cucumis melo L.). In: Proceedings of Eucarpia Meeting on Cucurbit Genetics and Breeding. Avignon Monfavet, France, pp 119-128.

Schreinemachers, P., Simmons, E.B. and Wopereis, M.C.S. (2018). Tapping the economic and nutritional power of vegetables. Global Food Security. 16: 36-45.

Shariatpanahi, E.M. and Ramezanpour, S.S. (2019). Induction of parthenogenetic haploid embryos and production of haploid plants in cucumber (Cucumis sativus L.). Journal of Plant Production Research. 26(1): 21-33.

Shmykova, N., Domblides, E., Vjurtts, T., Domblides, A. (2021). Haploid embryogenesis in isolated microspore culture of carrots (Daucus carota L.). Life. 11: 20-26.

Shumilina, D., Kornyukhin, D., Domblides, E., Soldatenko, A. and Artemyeva, A. (2020). Eûects of genotype and culture conditions on microspore embryogenesis and plant regeneration in Brassica rapa ssp. rapa L. Plants. 9(2): 278-287.

Solmaz, I., Sarı, N., Gu "rsoy, I. and Kasapog 'lu, S. (2011). Comparison of in vivo and in vitro colchicine application for production of dihaploid 'Kirkagac' and 'Yuva Hasanbey' melons. Afr. J. Biotechnol. 10(70): 15717-15724.

Song, H., Lou, Q.F., Luo, X.D., Wolukau, J.N., Diao, W.P., Qian, C.T. and Chen, J.F. (2007). Regeneration of doubled haploid plants by androgenesis of cucumber (Cucumis sativus L.). Plant Cell Tiss. Org. Cult. 90(3): 245-254. 
Sorntip, A., Poolsawat, O., Kativat, C. and.Tantasawat, P.A. (2017). Gynogenesis and doubled haploid production from unpollinated ovary culture of cucumber (Cucumis sativus L.). Can. J. of Plant Sci. 98(2): 353-361.

Sun, S.R., Zhai, Q. H., Hu, J. B., Chen, J. F. and Zhang, P. (2009). Effects of several physiological factors on embryo formation in unpollinated ovary culture of pumpkin (Cucurbita moschata). Plant Physiol. Commun. 45(10): 977-980.

Supena, E., Suharsono, S., Jacobsen, E. and Custers, J. (2006). Successful development of a shed-microsporeculture protocol for doubled haploid production in Indonesian hot pepper (Capsicum annuum L.). Plant Cell Rep. 25: 1-10.

Szarejko, I. and Forster, B.P. (2006). Doubled haploidy and induced mutation. Euphytica. DOI: 10.1007/s10681-006-9241-1.

Taskın, H., Yucel, N.K., Baktemur, G., Comlekcioglu, S. and Buyukalaca, S. (2013). Effects of different genotypes and gamma ray doses on haploidization with irradiated pollen technique in watermelon (Citrullus lanatus L.). Can. J. Plant Sci. 93(6): 1165-1168.

Thaneshwari Kumari, P. and Aswath, C. (2018). Haploid and double haploids in ornamentals - A review. Int. J. Cur. Microbiol. Appl. Sci. 7: 2319-7706.

Touraev, A., Indrianto, A.; Wratschko, I., Vicente, O. and HeberleBors, E. (1996). Efficient microspore embryogenesis in wheat (Triticum aestivum L.) induced by starvation at high temperatures. Sex. Plant Reprod. 9(5): 209-215.

Touraev, A. et al. (2001) The microspore: a haploid multipurpose cell. Adv. Bot. Res. 35: 53-109.

Tsay, H.S. (1996). Haploidy in Asparagus Anther Culture. In: In vitro Haploid Production in Higher Plants. [Jain, S.M.,
Sopory, S.K. and. Veilleux, R.E. (Eds.)] Kluwer Academic Publishers, Dordrecht, pp. 109-134.

Tuncer, B. (2017). Callus formation from isolated microspore culture in radish (Raphanus sativus L.). The J. Animal and Plant Sci. 27(1): 277-282.

Wędzony, M., Forster, B.P., Żur, I., Golemiec, E., SzechyńskaHebda, M., Dubas, E. and Gotębiowska, G. (2009). Progress in Doubled Haploid Technology in Higher Plants. In: Advances in Haploid Production in Higher Plants. Springer, Netherlands. 1-33.

Zaki, M. and Dickinson, H. (1990). Structural changes during the first divisions of embryos resulting from anther and free microspore culture in Brassica napus. Protoplasma. 156: 149-162.

Zhang, Y.B., Chen, J.F., Yi, H.P., Lei, C. and Wu, M.Z. (2006). Induction of haploid melon (Cucumis melo) plants by pollination with irradiated pollens. J. Fruit Sci. 23(6): 892895.

Zhang, Y., Wang, A., Liu, Y. and Feng, H. (2012). Improved production of doubled haploids in Brassica rapa through microspore culture. Plant Breed. 131: 164-169.

Zhao, H., Wang, X., Yong-chen, D, De-wei, Z, Yan-mei, G., Jianchang, G., Fei, L. and Snyder, J.C. (2014). Haploid induction via in vitro Gynogenesis in tomato (Solanum lycopersicum L.). J. Integrative Agric. 3119(13): 60672-3.

Zou, T., Song, H., Chu, X. Tong, L. and Liang, S., Gong, S., Yang, H. and Sun, X. (2020). Efficient induction of gynogenesis through unfertilized ovary culture with winter squash (Cucurbita maxima Duch.) and pumpkin (Cucurbita moschata Duch.). Scientia Horticulturae. 264: 109-152. 